\title{
Consideration of Ruptured Cerebral Aneurysms Clipping Surgery
}

\author{
Sang-Ku Park, Dong-Jun Kim and Hung-Tae Han \\ Department of Neurology, Samsung Medical Center, Seoul 135-710, Korea
}

\begin{abstract}
To measure motor evoked potentials (MEP) during emergency surgery is often difficult in patients with subarachnoid hemorrhage (SAH) from a ruptured cerebral aneurysm, The cause of these difficulties may be considered as damage to the motor pathway by hemorrhage. To identify the cause of difficulties in measuring MEP, we defined the association between motor evoked potentials during surgery and the severity of the hemorrhage in patients with subarachnoid hemorrhage.
\end{abstract}

Keywords: Motor evoked potentials, Subarachnoid hemorrhage

This is an Open Access article distributed under the terms of the Creative Commons Attribution Non-Commercial License (http://creativecommons.org/licenses/by-nc/3.0) which permits unrestricted non-commercial use, distribution, and reproduction in any medium, provided the original work is properly cited.

Copyright (C) 2015 The Korean Society for Clinical Laboratory Science. All rights reserved.
Corresponding author: Dong-Jun Kim

Department of Neurology Laboratory, Samsung Medical Center, Seoul 135-710, Korea Tel: 82-2-3410-2737

E-mail: djbear.kim@samsung.com

Received: February 27, 2015

Revised: March 15, 2015

Accepted: March 16, 2015

\section{서 론}

우리나라 사망인구 원인 중 1,2 위를 다투는 질환은 뇌혈관질환 으로 해마다 증가하고 있는 추세이다. 서구화된 식습관과 생활습관 등으로 발생률이 증가하고 있다고 추정된다. 뇌동맥류(cerebral aneurysms)는 비파열성과파열성으로 구분이 되며, 파열성은 우리가 흔히 아는 뇌출혈이라 불리는 것으로 지주막하출혈(subarachnoid hemorrhage, $\mathrm{SAH}$ )이라고 하는 뇌동맥이 파열되어서 심각한 의식 장애를 동반하고 응급으로 수술을 하여야 하는 상황을 초래한다. 발생원인으로 후천적으로 혈관에 가해지는 압력이 지속적으로 강 하게 가해져서 뇌동맥류가 발생한다고 지목 되고 있고, 매년 인구 10 만명당 약 $10 \sim 20$ 명 정도 발생하며 3:2 정도의 비율로 여자에 서 많이 발생하고, 특히 내경동맥(internal carotid artery) 동맥류 는 여자에게 자주 발생 하고, 40 세 이전의 젊은 연령층에 흔하며, 전 교통동맥(anterior communication artery: $\mathrm{ACOA}$ ) 동맥류는 남자 에서 많이 발생하고, 40 60세의 연령에서 가장 흔하다. 뇌동맥류 가족력을 가진 사람과 흡연하는 사람들에게서 더 많이 발생하고, 흡연 시에는 혈중에 단백분해 효소가 분비되므로 혈관의 교원섬유 와 탄력섬유를 파괴시켜 뇌동맥류의 발생률을 높인다. 뇌동맥류가 파열되어 뇌지주막하출혈을 야기시키면 머리를 꽝 치는 듯한 느낌 과 함께 생애에서 가장 심한 두통을 경험하게 된다. 약 45\%는 5 10
분 정도 정신을 잃는데, 이는 뇌동맥류가 파열되면 갑자기 뇌압이 상승하여 일시적으로 뇌혈류가 중지되기 때문이다. 뇌동맥류 파열 시 약 $15 \%$ 정도는 출혈이 심하여 회복하지 못하고 사망한다.

뇌동맥류는 비파열 된 경우 자기공명영상(MRI)을 이용한 혈관 조영술로 진단이 가능하고, 파열된 경우는 전산화 단층촬영(CT), 뇌혈관 조영술(cerebral angiogram)을 사용하여 출혈의 위치를 파악할 수 있다(Tarr RW 등, 1994 ; Symon L, 1995 ; Baxter AB 등, 1998 ; Connolly ES 등, 1998). 수술 중에는 뇌혈관 조영술, 혈관에 서 직접 측정하는 경두개 도플러(transcranial doppler, TCD)를 사용하여 수술이 잘 되었는지를 파악을 하고 있으며, 수술 중 신경 계 집중감시검사-Intraoperative neurophysiological monitoring, $\mathrm{INM}$ )를 통하여 보다 완벽하게 환자의 상태를 파악할 수 있다.

뇌동맥류 파열 응급 수술을 시행할 때 수술 후 환자의 한쪽 팔 또 는 다리의 운동성 저하를 방지하고자 수술 중 신경계 감시검사가 시행이 되고 있으나, 파열된 뇌동맥류 수술 시에만 특이하게 운동 유발전위 검사의 파형 측정이 원활하지 않은 것과 응급 전산화 단 층촬영(CT)에서의 출혈(hemorrhage) 정도를 나타내는 Fisher 등 급(grade)과의 관계에 대하여 알아보고자 한다. 


\section{재료 및 방법}

\section{1. 검사장비}

수술장에서 사용하는 신경계추적감시(INM)검사장비는 Xltek Protektor (Natus Medical Incorporated Excel Tech Ltd., XLTEK, Canada)를 사용하였다. 운동유발전위(Motor Evoked Potentials, MEP) 검사 setting은 Range $\pm 2.5 \mathrm{mV}$, Reject Threshold $\pm 1.5 \mathrm{mV}$, LFF/HFF: $10 \mathrm{~Hz} / 1 \mathrm{KHz}$, Timebase 10 $\mathrm{ms} / \mathrm{div}$ 로 설정하여 검사를 하였다.

\section{2. 검사방법}

2010년 1월부터 2014년 7월까지 삼성서울병원에서 파열성 뇌 동맥류(뇌출혈)로 응급실 내원하여 응급수술을 시행한 74 명의 환 자를 대상으로 하였다(Table 1).

뇌동맥류 목묶음술(cerebral aneurysm clipping)을 시행하는 동안 운동유발전위(MEP) 와 체성감각유발전위(SSEP) 검사를 시 행하였으며, 검사 중 복합근운동전위(CMAP) 형성에 대한 마취효 과를 최소화 하기 위하여, 마취gas를 배제한 완전정맥마취(Total intravenous anesthesia, TIVA)로 전신마취 유도하였다. 침전극 (Subdermal needle electrodes)을 이용하여 파형을 기록할 상지 에는 단모지외전근(muscle abductor pollicis brevis, $\mathrm{APB}$ )와 소 지외전근(muscle abductor digiti quinti, $\mathrm{ADQ}$ )에서, 하지에는 전 경골근(muscle tibialis anterior, $\mathrm{TA}$ )와 무지외전근(muscle abductor halluces, $\mathrm{AH}$ )에 삽입하였고, 운동유발전위 자극할 부 위는 뇌파(EEG) 전극부착법인 10-20 부착법(system)에 의거하여 C3, C4에 300 400 볼트(voltage)의 전기적 자극(electrical stimulation)을 하여 파형을 기록하였다. 파열된 동맥류 응급수술

Table 1. General characteristics in 74 patients

\begin{tabular}{lc}
\hline No. of patients 74 & \\
\hline Female : male (ratio) & $44: 30(1: 0.68)$ \\
Mean age (yrs) & $23 \sim 79(54.7)$ \\
Operation side (Lt : Rt) & $38: 36$ \\
Fisher Grade 3 & 7 \\
Fisher Grade 4 & 11 \\
\hline
\end{tabular}

에서만 보이는 비정상적인 검사파형과 이러한 파형이 어떠한 과정 을 거쳐야 정상적으로 형성되는지 살펴보았다.

\section{3. 마취의 영향}

수술은 전신마취 하에 이루어지므로 마취의 심도에 파형이 영향 을 받는다. 마취의 심도가 너무 깊으면 운동유발전위 파형이 형성 안 된다. 그러므로 척골신경을 4 번 연속적으로 자극한 후 엄지손가 락의 움직임을 관찰하는 사연속자극(train of four, TOF)검사가 적 어도 2번 이상 되도록 근이완제(neuromuscular blocking agent) 의 양을 적절히 유지하는 것이 중요하다. 신경계 감시 검사를 위하 여 마취과에서 마취의 심도를 너무 낮게 유지할 경우에 가끔 수술 중에 환자가 깨기도 한다. 수술 중 환자의 의식이 깨어나게 되면 수 술 부위로 인한 극심한 통증을 순간적으로 매우 크게 느끼게 되고, 자발호흡을 하려 하지만 기도 삽관이 되어있어서 원활하게 호흡을 할 수 없는 상태여서 매우 짧은 시간에 혈압이 최고치에 오르게 되 고, 심박동수는 매우 빠르게 바뀐다. 자칫 수술로 인하여 연약한 부 위가 외부에 노출이 되어있는 상태라면 혈압의 급상승으로 뇌혈관 이 파열될 수도 있으므로 마취과의사와 신경계검사자 간에 상호 협 조가 매우 긴밀하게 이루어 지도록 하였다(Sang-Ku Park 등, 2012).

\section{결 과}

뇌출혈이 발생하여 머리 속에 피가 고인 상태를 응급 전산화 단 층촬영(CT)으로 출혈(hemorrhage) 정도를 나타내는 Fisher Grade가 있다. 자세히 살펴보자면, Gr 1은 검사 상 명확한 근거는

Table 2. The Fisher Gradeclassifies the appearance of subarachnoid hemorrhage on $\mathrm{CT}$ scan

\begin{tabular}{cc}
\hline Grade & \multicolumn{1}{c}{ Explanation } \\
\hline Grade 1 & No hemorrhage evident \\
Grade 2 & Subarachnoid hemorrhage less than 1 mm thick \\
Grade 3 & $\begin{array}{c}\text { Subarachnoid hemorrhage more than 1 mm thick } \\
\text { Grade 4 } \\
\text { Subarachnoid hemorrhage of any thickness with } \\
\text { intra-ventricular hemorrhage (IVH) or intracranial } \\
\text { hemorrhage (ICH) }\end{array}$ \\
\hline
\end{tabular}

Table 3. Fisher grade and Motor evoked potentials wave forms

\begin{tabular}{cccccccc}
\hline \multirow{2}{*}{ Baseline MEP } & \multicolumn{2}{c}{ Waveform is observed as a significant difference } & & \multicolumn{3}{c}{ Not observing the waveform } \\
\cline { 2 - 3 } & Upper \& Lower & Upper & Lower & & Upper \& Lower & Upper & Lower \\
\hline Fisher Gr. 1 & 0 & 0 & 0 & 0 & 0 & 0 & 0 \\
Fisher Gr. 2 & 0 & 0 & 0 & 0 & 1 & 0 \\
Fisher Gr. 3 & 4 & 0 & 0 & 5 & 1 & 1 \\
Fisher Gr. 4 & 1 & 0 & 0 & & 0 \\
\hline
\end{tabular}


없지만 hemorrhage가 의심되는 정도이고, $\mathrm{Gr}$ 2는 $1 \mathrm{~mm}$ 이하의 hemorrhage가 관찰되는 상태이고, $\mathrm{Gr} 3$ 는 $1 \mathrm{~mm}$ 이상의 hemorrhage가 관찰되는 상태이고, $\mathrm{Gr}$ 4는 뇌 실질 내 출혈 (intracranial hemorrhage, ICH) 또는 뇌 실내 출혈(intraventricular hemorrhage, IVH)이 동반 관찰되었을 때로 나뉘며, 본원 응급실로 내원한 모든 환자는 전산화 단층촬영(CT)을 시행하 였고 삼성서울병원 신경외과 전문의가 Fisher 등급(grade) 분류기 준에 근거하여 모두 분류하였다(Table 2,3).

전체 74 명 중 수술 초반부터 운동유발전위(MEP) 파형형성이 안 되거나좌, 우측 유의한 차이를 보인 경우는 13 명이며, 파형은 형성 되었지만 유의한 차이(파형의 진폭이 좌측과 우측이 비슷하지 않고 차이가 나는 경우)가 관찰된 경우는 5명, 편측 상하지 모두 파형측 정이 안된 경우는 5 명, 상지만 파형측정이 안된 경우는 2 명, 하지 만 파형측정이 안된 경우는 1 명이었다. 그 중 Fisher 등급 4가 13명 중
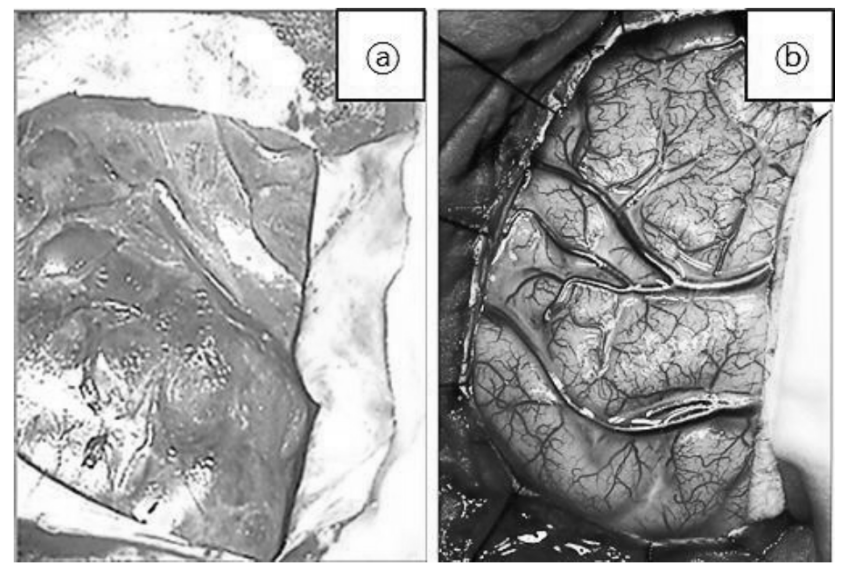

Fig. 1. Brain hemorrhage and brain hemorrhage removal.
8 명이었다. 전체 환자 중 Fisher 등급 4 는 총 11 명이었고 이중 8 명 에서 MEP 파형의 형성이 원활하게 이루어지지 않을 수 있음을 알 수 있으며, 전체 74 명 뇌출혈 환자의 $10.8 \%$ 에 해당하는 수치이고 Fisher 등급 4에서는 $72.7 \%$ 의 수치이다. Fisher 등급 3일 때에는 전체환자 중 $6.8 \%$ 에 해당하는 수치이고 Fisher 등급 3에서는 $71.4 \%$ 의 수치이다. 이러한 경우 운동유발전위 기본측정(baseline $\mathrm{MEP}$ )을 설정하는 시점은 뇌 경막을 연(dura open) 후 뇌에 고인 피 떡(hemorrhage)의 제거가 어느 정도 이루어진 후의 시점으로 해 야 원활하게 측정됨을 알 수 있었다. 뇌 표면에 뇌출혈 피떡이 고여 서 환자의 의식 장애뿐 만 아니라 운동유발전위 측정도 원활하지 않는 경우(Fig. 1a, Fig. 2a)와 피떡을 제거한 이후에 운동유발전위 파형이 원활하게 측정되는 경우(Fig. 1b, Fig. 2b).

\section{고 찰}

뇌동맥류의 수술적 치료의 가장 큰 목적은 정상적인 혈류로부터 뇌동맥류를 완전히 폐쇄시켜 재출혈을 방지하는데 있다. 비파열 뇌 동맥류를 조기에 발견하여 수술을 하는 결과로 이환률(morbidity) 와 사망률(mortality)이 상당히 감소하였다(Zabramski JM 등, 1995). 뇌출혈로 인하여 엠불런스를 타고 응급실로 실려와서 응급 수술을 하게 되는 수술에서 수술 중 집중감시 검사 시행 시 한쪽부 위의 운동유발전위 파형만이 관찰되고 한쪽은 관찰되지 않는다면 지주막하출혈(subarachnoid hemorrhage, $\mathrm{SAH}$ ) 수술의 응급성 을 감안하였을 때 상당히 당황스런 경우일 수 있으나, 수술 전 Fisher 등급(grade)과 같은 환자의 상황을 꼼꼼히 체크한다면 이론 적, 실무적으로 대처하는데 상당히 도움이 되리라 생각하고, 수술 후 환자의 신경계적 후유증을 최소화 하는데 궁극적인 목적이 있으
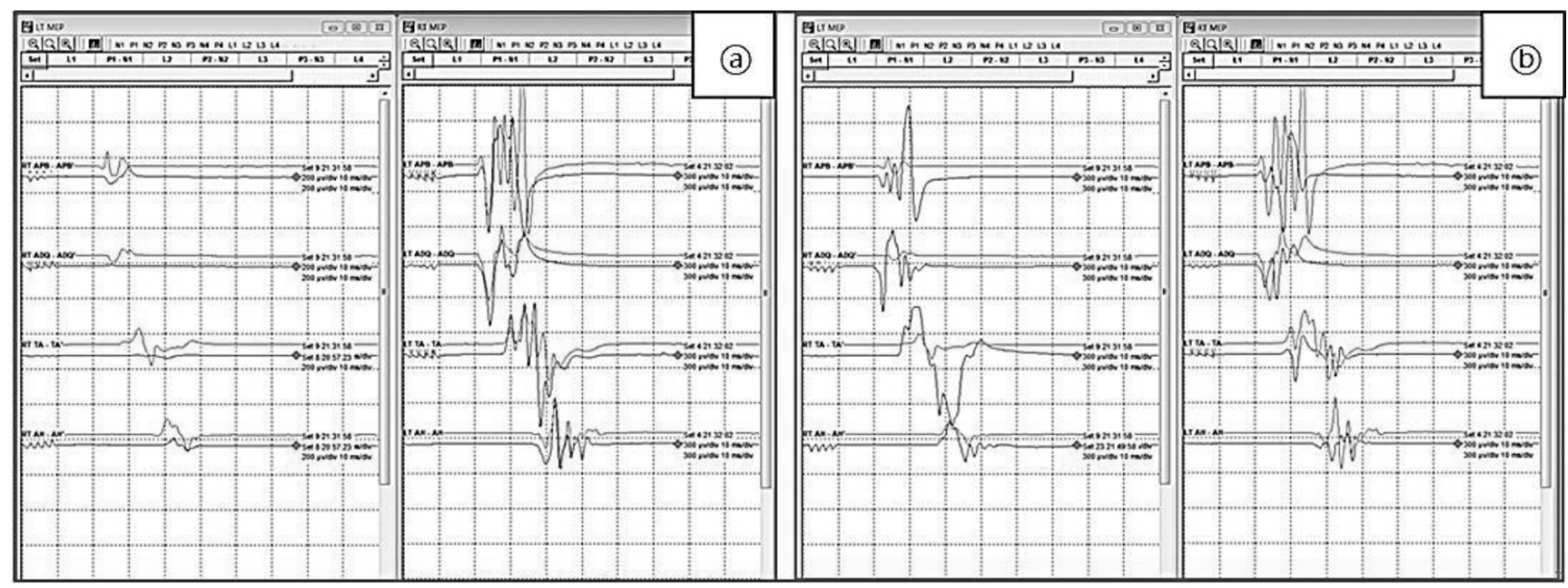

Fig. 2. Significant difference motor evoked potentials wave form (a) and normal motor evoked potentials wave form (b). 
므로 사소하지만 작은 가능성을 항상 염두 해 가며 검사에 임해야 할 것이다.

Acknowledgements: None

Funding: None

Conflict of interest: None

\section{References}

1. Baxter AB, Cohen WA, Maravilla KR : Imaging of intracranial aneurysms and subarachnoid hemorrhage. Current management of cerebral aneurysms, Part 1 : Evaluation and perioperative care. Neurosurgery clinics of North America, edited by M. Mayberg, pp445-462. Saunders, Philadelphia, 1998.

2. Connolly ES, Solomon RA : Management of sysmtomatic and asymptomatic unruptured aneurysms. Current management of cerebral aneurysms, Part 1 : Evaluation and perioperative care. Neurosurgery clinics of North America, edited by M. Mayberg, 509-524. Saunders, Philadelphia, 1998.

3. Sang-Ku Park, Sung-Hyuk Lim, Chan-Woo Park, et al, Intra-operative Neurological Monitoring and Anesthesia. Korean J Clin Lab Sci. 2012, 44(4) : 184-198.

4. Symon L : Surgical management of Middle cerebral artery aneurysms, in Schmidek HH, Sweet WH(eds) : Operative Neurosurgical Techniques, Indications, Methods, and Results $3^{\text {rd }}$ ed. Vol. 1. W.B. Saunders, Co., Philadelphia, 1995.

5. Tarr RW, Perl J II, Masaryk TJ : Neuroradiological aspects of aneurysms. Ratcheson RA. Wirth FP(eds). In Ruptured cerebral aneurysms : Perioperative management, Concepts in Neurosurgery. Vol. 6, pp182-203. Williams \& Wilkins, 1994.

6. Zabramski JM, Hamilton MG : Cerebral vasospasm. Caretr LP, Spetzler RF(eds) Neurovascular Surgery. McGraw-Hill, New York, 1995. 